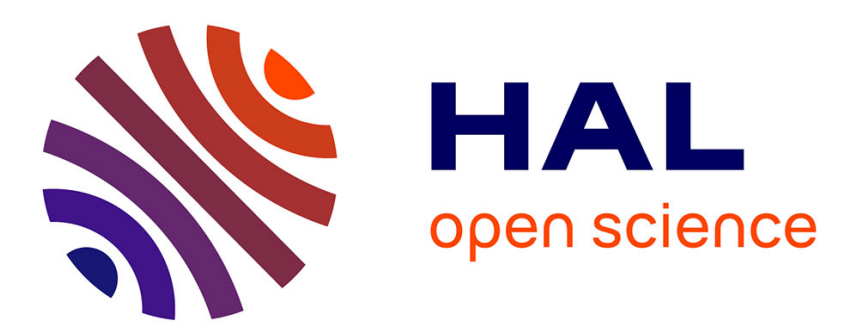

\title{
Processing evidentiality in bilingualism and aphasia: an overview of some recent studies on Turkish
}

Seçkin Arslan

\section{To cite this version:}

Seçkin Arslan. Processing evidentiality in bilingualism and aphasia: an overview of some recent studies on Turkish. Evidentials and Modals, Brill, In press. hal-02470338

\section{HAL Id: hal-02470338 \\ https://hal.science/hal-02470338}

Submitted on 11 Feb 2020

HAL is a multi-disciplinary open access archive for the deposit and dissemination of scientific research documents, whether they are published or not. The documents may come from teaching and research institutions in France or abroad, or from public or private research centers.
L'archive ouverte pluridisciplinaire HAL, est destinée au dépôt et à la diffusion de documents scientifiques de niveau recherche, publiés ou non, émanant des établissements d'enseignement et de recherche français ou étrangers, des laboratoires publics ou privés. 
Subm. to "Evidentials and Modals" Lee \& Park (Eds)

\section{Processing evidentiality in bilingualism and aphasia: an overview of some recent studies on Turkish}

\section{Seçkin Arslan}

Laboratorie Bases, Corpus, Langage (BCL), Université Côte d'Azur, CNRS, Nice, France

Address correspondence to

Dr. Seçkin Arslan, seckin1984@gmail.com

Laboratoire BCL: Bases, Corpus, Langage - UMR 7320

CNRS - Université Côte d'Azur

Campus Saint Jean d'Angely - SJA3 / MSHS-SE

Bâtiment de l'Horloge

24 , avenue des diables bleus

06357 Nice CEDEX 4 


\section{Abstract}

Evidentiality, the linguistic indication of information sources from which a speaker knows his statement, is grammatically obligatory and is expressed through inflectional morphology for direct and indirect information sources in Turkish. Although it is a rather well-studied system regarding its theoretical basis and its acquisition in children, experimental studies targeting persons with aphasia or bilingual individuals measuring time-sensitive aspects of evidentiality processing are scant. This chapter provides an overview of evidentiality in Turkish and details out recent neurolinguistic and psycholinguistic studies on evidentiality in this language, reporting the time-course of evidentiality processing evidenced with timed sentence verification, eye-tracking and other behavioural data. In the light of these data, the chapter evaluates some controversies on evidentiality in Turkish, making clear implications as to how evidentiality processing is modulated by psycholinguistic and neurolinguistic factors.

Keywords: Turkish; evidentiality; time reference; source memory; bilingualism; aphasia; information source 


\section{INTRODUCTION}

Turkish marks evidentiality, the grammatical category that signals information sources via which a speaker knows the information in his statement, through its tense-aspect-mood suffixes appended to the verb. Turkish evidentials are inflectional forms that are suffixed to finite verbs and non-verbal predicates. Two evidential forms are available in Turkish: the direct evidential, whose function is to signal that information expressed in a proposition comes from a firsthand source (e.g. speaker's own experience), and the indirect evidential, which encodes that information is based on a non-firsthand source. The direct evidential is marked with the morpheme -DI to indicate one's direct information sources while the indirect evidential is marked with the morpheme -mIş to signal indirect information sources, which include the speaker's inference based on 'resultant states of an action' and/or report from another speaker (Slobin and Aksu 1982, Aksu-Koç and Slobin 1986).

Evidentiality in Turkish is more commonly marked for past events and states. By default, when evidential suffixes are attached to verb stems, they express past time reference. Thus, a Turkish speaker has to select one of the two evidential suffixes in order to talk about a past event, as illustrated in (1)-(2).

\begin{tabular}{|l|l|l|l|}
\hline$(1)$ & Vasili & $k$ kutuy- $u$ & $a c ̧-t \imath$ \\
\hline & Vasili & box-ACC & open-DIRECT EVID-3SG. \\
\hline & \multicolumn{2}{|l|}{ "Vasili opened the box" (speaker witnessed this event) } \\
\hline
\end{tabular}

\begin{tabular}{|l|l|l|l|}
\hline$(2)$ & Vasili & kutuy-u & $a c ̧-m ı s ̧$ \\
\hline & Vasili & box-ACC & open-INDIRECT EVID-3SG. \\
\hline & \multicolumn{2}{|c|}{ "Vasili opened the box" (speaker has non-firsthand information) } \\
\hline
\end{tabular}


In (1), what licences the use of a direct evidential is the speaker's direct experience, most probably through eye-witnessing. In (2), however, the use of an indirect evidential signals that the speaker has either inferred the action or was reported about it by another speaker.

\section{Evidentials in Turkish}

\subsection{Direct evidential -DI}

The evidential status of the direct evidential form -DI is well-established in Turkish linguistics since the early studies. To enumerate, Underhill described the direct evidential as the definite past, the use of which is appropriate for contexts "when the speaker has personally witnessed the action that he describes" (Underhill 1976, p. 169). Aksu-Koç and Slobin defined the direct evidential marker as the "past of the direct experience" (Aksu-Koç and Slobin 1986, Slobin and Aksu 1982). Marking of direct experience includes an assortment of contexts, such as visual firsthand evidence, speaker's participation in the event and non-visual sensory evidence.1 See for examples in (3)-(5).

\begin{tabular}{|l|l|l|l|}
\hline (3) & Poyraz & kumsal-a & koş-tu \\
\hline & Poyraz & beach-DAT & run-DIRECT EVID-3SG. \\
\hline & \multicolumn{3}{|c|}{ "Poyraz ran to the beach" (the speaker witnessed him running) } \\
\hline
\end{tabular}

\begin{tabular}{|l|l|l|l|l|}
\hline (4) & Adam & bizim-le & top & oyna-d $l$ \\
\hline & Poyraz & us-INSTR & ball & $\begin{array}{l}\text { play-DIRECT } \\
\text { EVID-3SG. }\end{array}$ \\
\hline & $\begin{array}{l}\text { "The man played football with us" (participatory firsthand evidence) } \\
\text { (Arslan 2015) }\end{array}$ \\
\hline
\end{tabular}

\footnotetext{
1 Note that well-assimilated events in the history, which the speaker was not involved in or witnessed directly,
} may also be marked with a direct evidential, see Plungian (2010) for discussions. 


\begin{tabular}{|l|l|l|l|}
\hline$(5)$ & Mutfak & yanık & kok-tu \\
\hline & Kitchen & burnt & smell-DIRECT EVID-3SG. \\
\hline & \multicolumn{2}{|l|}{ "Kitchen smelled burnt" (sensory firsthand evidence) } \\
\hline
\end{tabular}

The use of a direct evidential in (3) is affiliated with the fact that the speaker has eye-witnessed the event himself while in (4) the use of a direct evidential is licenced by the speaker's participatory firsthand evidence. That is, the speaker participated in this event. Finally, the direct evidential used in (5) encodes that the speaker has non-visual sensory firsthand evidence, possibly through smelling the smoke. Essentially, different kinds of firsthand evidence map into only one marker in Turkish, the direct evidential form.

One controversy in Turkish linguistics is that, unlike the volumes of studies presented above, Johanson (2003) argues that -DI, the direct evidential form as referred to here, is an evidentiality-neutral past tense. According to Johanson, the morpheme -DI does not "consistently indicate direct experience or speaker's direct involvement in the event" (2003, p. 275).

\subsection{Indirect evidential $-\mathrm{mIş}$}

The indirect evidential has been defined as the expression of the speaker's access to nonfirsthand evidence about an event being described (Cinque 2001, Johanson 1971, Csató 2000), indicating that information about the event is new to the speaker's knowledge (Underhill 1976, Aksu-Koç 2000). This evidential form functions to mark two different kinds of non-firsthand evidence: inference and reportative, as illustrated in (6).

\begin{tabular}{|l|l|l|l|}
\hline (6) & Poyraz & kumsal-a & koş-muş \\
\hline & Poyraz & beach-DAT & run-INDIRECT EVID-3SG \\
\hline
\end{tabular}




\begin{tabular}{|l|l|}
\hline & "Poyraz ran to the beach" (non-witnessed information: inference or report)
\end{tabular}

It is possible that the speaker may have access to one of the two forms of non-firsthand evidence when s/he uttered the statement in (6). First possibility is that the speaker's use of an indirect evidential here is linked with a report of another speaker. In other words, the speaker was told about it and no stage of this event was witnessed by the speaker himself. Second possibility is that the speaker used an indirect evidential in that s/he inferred that this event happened, probably through accessing pieces of evidence based on results of the event (e.g. seeing footprints on the beach), leading the speaker to infer that the event had happened.

\subsection{Time reference and evidentiality interface}

As argued above, Turkish evidentials refer to the past, which brings us to another controversy within the theoretical approaches to Turkish evidentials: are they past tenses in the traditional sense? Conventionally, these forms are argued to be 'past tenses'. When appended on simple verb stems, both the evidentials mark past tense/perfect aspect (e.g., Kornfilt 1997, Erguvanl1Taylan 1997, Johanson 2003). However, temporal characteristics of evidentials have been reconsidered in recent analyses and it is proposed that evidentials may behave differently from tenses in terms of their time reference. See, for instance, Aikhenvald (2004, p. 99) who states that "time reference of an evidential does not have to coincide with that of the event". This is based on the fact that an evidential may make reference to an actual event in the past but also to the time when the speaker receives information on this event, which could be different to the actual event time.

When these analyses are applied to Turkish evidentials, the following arguments are obtained. The direct evidential makes past time reference as both the actual event time and the time of witnessing overlap in the past. However, the picture is more complicated for the indirect evidential $-\mathrm{mIss}$, in which the actual event time is different relative to the time when information 
is received by the speaker. More specifically, the actual event occurs before the speaker gets to know about it. Therefore, it is conceivable that the indirect evidential shifts to non-past readings depending on when the information arrives to the speaker, where the actual event time is not relevant any more (Arslan et al. 2014), see also Enç (2004) for discussions.

\section{Empirical studies on evidentiality}

A large volume of research on evidentiality comes from theoretical and sociolinguistic studies, which primarily deal with theorizing evidentiality systems and describing these systems in world languages (e.g. Chafe and Nichols 1986, Aikhenvald 2003, Johanson and Utas 2000). The current understanding of cognitive aspects in evidentiality processing, however, at least in Turkish, mostly depends on investigations into (monolingual) children's acquisition of evidentiality, which include pioneering seminal works of Aksu-Koç (1988). These studies showed that, in Turkish, the direct evidential is acquired relatively earlier than its indirect counterpart and that young children (i.e. aged 3-6) are not fully able to identify different information sources that are embodied in the evidential suffixes (Aksu-Koç, Ögel-Balaban, and Alp 2009, Ozturk and Papafragou 2016). Similar difficulties acquiring evidentiality have also been observed in Korean, another evidential language, showing that at very young ages (3-4) children tend to produce evidential forms correctly whereas their comprehension of these forms is unstable at this stage (Papafragou et al. 2007). In summary, the acquisition literature has shown that Turkish children acquire the indirect evidential later than the direct one, and at young ages children are less able to comprehend evidentials, possibly because, at this stage of cognitive development, children are unable to discriminate different information sources.

Although, the previous literature has significant contributions to the basis of our current scientific knowledge on evidentiality processing, only a little has been explored on the other side of the medal, leaving gaps in knowledge on processing of evidentials in less commonly studied 'adult' speakers, such as persons with language disorders, or bilingual speakers. The 
aim of this chapter is to recap recently emerging experimental findings from studies that investigated the processing of Turkish evidentials in less commonly studied populations. In the next sections, I will provide an overview of how evidentials are affected in bilingual Turkish speakers living under heritage language conditions and how they are impaired in aphasia.

\subsection{Attrition in evidentials: perspectives from bilingual processing}

Early studies on Turkish bilingual speakers' attainment of evidentiality are rather restricted to narrative speech studies. For instance, (Pfaff 1991, 1993) examined child Turkish heritage speakers2 in Germany using free-speech production tasks; Aarssen (2001) investigated Turkish child heritage speakers in the Netherlands and Karakoç (2007) those living in Germany using narrative speech elicitation tasks based on stories. These studies showed that child Turkish heritage speakers make inconsistent uses of evidentiality marking when contrasted to their Turkish monolingual peers, suggesting that in childhood bilingualism stabilization of evidentiality may be delayed.

Arslan, Bastiaanse, and Felser (2015) tested groups of Turkish monolingual speakers, early and late Turkish-German bilinguals using a visual-word setting in which participants' eye-movements were monitored while they listened to sentences marked with either direct and indirect evidentiality. Their data showed that both the bilingual groups had less accurate responses and reduced proportions of looks to the target pictures for sentences with direct evidentials than those with indirect evidentials. In their processing of the direct evidential form, the Turkish monolingual speakers showed an interesting pattern: they turned their gaze toward the context picture, where an action's in-progress version was shown, before they fixated on the target picture, which depicts the action's end-stage. The authors interpreted this eyemovement pattern as an indication that the monolingual speakers needed to "verify that the

\footnotetext{
2 The term "heritage speaker" here is referred to as early or simultaneous bilinguals who typically acquire a minority language in family settings and a dominant majority language spoken by the society.
} 
action could indeed be witnessed directly' as they were looking for evidence (Arslan, Bastiaanse, and Felser 2015, p. 12). However, such a pattern was less pronounced in the bilingual groups' eye-movements.

Arslan, de Kok, and Bastiaanse (2017), with a sentence verification task, investigated a group of adult Turkish heritage speakers living in The Netherlands as compared to a group of monolingual Turkish speakers. The participants listened to sentences, as illustrated in (7)-(8), including a contextual support clause where the information source perspective was set to either firsthand information (7) or to non-firsthand information. The assumption was that a verb form inflected with the direct evidential within a non-firsthand information context, as well as an indirect evidential within a firsthand information context, would be counter-intuitive to Turkish native speakers.

\begin{tabular}{|l|l|l|l|l|l|l|l|}
\hline (6) & Yerken & gör-dü-m & az & önce & adam & yemeğ- $i$ & ye-miş \\
\hline & Eat & $\begin{array}{l}\text { see-DIRECT } \\
\text { EVID-1SG. }\end{array}$ & just & before & man & $\begin{array}{l}\text { meal- } \\
\text { ACC }\end{array}$ & $\begin{array}{l}\text { eat- } \\
\text { INDIRECT } \\
\text { EVID-3SG. }\end{array}$ \\
\hline & $\begin{array}{l}\text { * "I saw the man eating, he ate the food." (firsthand information source - } \\
\text { indirect evidential mismatch) }\end{array}$ \\
\hline
\end{tabular}

\begin{tabular}{|l|l|l|l|l|l|l|l|}
\hline$(7)$ & Yerken & görmüşler & az & önce & adam & yeme g- $i$ & ye-di \\
\hline & Eat & $\begin{array}{l}\text { see- } \\
\text { INDIRECT } \\
\text { EVID-3PL }\end{array}$ & just & before & man & $\begin{array}{l}\text { meal- } \\
\text { ACC }\end{array}$ & $\begin{array}{l}\text { eat-DIRECT } \\
\text { EVID-3SG. }\end{array}$ \\
\hline & $\begin{array}{l}\text { *'They saw the man eating, he ate the food." (non-firsthand information } \\
\text { source - direct evidential mismatch) }\end{array}$ \\
\hline
\end{tabular}

The data showed that, in an offline rating task without any time constraints, Turkish native speakers evaluated both kinds of evidentiality mismatches to their corresponding information 
source contexts equally unacceptable. However, in an online task, for which the participants were asked to provide a button press as soon as they detect an unacceptability, the monolingual Turkish speakers were faster to respond to firsthand sources followed by the indirect evidential (7) than for non-firsthand sources followed by the direct evidential (8). Interestingly, however, the Turkish heritage speakers failed in this task: their performances in detecting evidentiality mismatches were around $32 \%$ of the time in both the conditions and they had much longer response time as compared to the monolinguals. This implies that the heritage speakers did not notice mismatches between information sources and the evidentiality markers in which these information sources are encoded, possibly because semantic and pragmatic features of evidentiality eroded in the bilingual speakers as a consequence of heritage language conditions (e.g. low quality input, existence of a dominant society language).

Arslan and Bastiaanse (Submitted) investigated appraisal of evidentiality in spontaneous speech production of a group of adult Turkish heritage speakers living in The Netherlands. The authors considered a number of bilingualism factors, including, proficiency, daily language use of Turkish/Dutch, and daily receptive exposure to these languages, in an attempt to explain why Turkish heritage speakers would show a non-target-like competence over the evidential forms. The data showed that although the heritage speakers produced equal numbers of verbs inflected with both the evidential forms as compared to monolingual peers, they made more inappropriate uses of the direct evidential in contexts where an indirect evidential would be more suitable. Furthermore, Arslan and Bastiaanse's (Submitted) analyses indicated that the most significant predictor of such contextually inappropriate uses of direct evidentials was the amount of receptive exposure to Turkish. According to the authors, heritage speakers who spend more than 2.88 hours per day listening and reading Turkish are more likely to use evidentiality correctly. 


\subsection{Breakdown in evidentiality processing: evidence from aphasia}

Arslan et al. (2014) conducted one of the very first investigations on evidentiality in aphasia, an acquired language disorder that occurs due to forms of brain damage or stroke. In this study, the authors examined the production of evidential forms and the ability to discriminate information sources that map into evidentials in a group of seven Turkish persons with aphasia (PWA). A sentence completion task was used, which required participants to complete simple sentences with a verb inflected either for direct or indirect evidential in three conditions: direct perception, inferential, and reportative. In a subsequent task, participants were assessed in their ability to identify from which information sources events presented in those sentences are known. The PWA were largely unable to produce the direct evidential form for the direct perception condition with $21 \%$ accuracy while they were rather spared in producing the indirect evidential form in inferential and reportative conditions (both 83\%). Interestingly, the PWA's source identification ability was impaired in the opposite direction: they were more successful in discriminating direct perception than inferred and reported information. Moreover, they made large portions of misattribution errors in identifying reportative and inferential information sources for which they 'thought to have witnessed' events presented in sentences with the indirect evidentiality.

These findings indicated that Turkish evidential forms are asymmetrically impaired in aphasic language production: direct evidentials are more affected than their indirect counterparts. According to Arslan et al. (2014), Turkish PWA's difficulty producing the direct evidential is linked to an impairment in processing discourse level information. More particularly, the direct evidential is assumed to be discourse-linked (i.e. referring to the preceding discourse) to a past event where the event time and the speaker's evaluation on the event overlap in the past. However, the indirect evidential is not discourse-linked, or nonspecific, as the actual event time does not correspond to the speaker's evaluation time, therefore, an event expressed with an indirect evidential is processed as new information. This line of 
reasoning is compatible with Bastiaanse and her colleagues' Past Discourse Linking Hypothesis (PADILIH, Bastiaanse et al. 2011), which holds that referring to discourse-linked past events and states is more effortful for PWA than referring to the non-past.

Arslan, Bamyac1 and Bastiaanse (2016) investigated the appraisal of verb forms in spontaneous speech production of ten Turkish speaking PWA, using open-end interview and picture description tasks. The PWA, having produced shorter and more incorrect utterances as compared to healthy individuals, had a rather normal rate of verb inflections, including the direct and indirect evidentials and present progressive forms. However, a detailed analysis showed that there was a trade-off pattern between the number of verbs used with the direct evidential and the diversity of those verbs, as measured by the type-token ratio. That is, some Turkish PWA produced large number of direct evidentials on only few types of verbs while some others who were able to use more diverse verbs had difficulty producing the direct evidential form. Such a pattern was not found in the production of indirect evidentials or present progressive forms. In short, the PWA produced similar amounts of evidential forms as healthy controls; nonetheless, information provided with the direct evidential was found to be reduced, as the diversity of verbs used with this form was lower than healthy controls, in line with the claims of Arslan et al. (2014).

An unexpected finding was distinguishing information sources that are embodied in evidentials showed an opposite direction of impairments in Turkish PWA's production of these evidential forms. This was addressed in Arslan and Bastiaanse (2014) who used a sourcememory task to investigate Turkish PWA's ability to attribute sources of memories in a groups of eight PWA, fifteen younger and five healthy aging individuals. In a study phase, the participants were presented with eighty inanimate objects, half of which were shown as visual objects (i.e. seen items, a picture of a balloon) and the other half were presented as spoken words (i.e. heard items). In a subsequent test phase, forty items from the study phase were mixed with another new forty items and were presented as written words. The participants were 
asked to make old/new judgements for each item presented, they were instructed to respond 'old' if an item was encountered in the study phase, if else to respond 'new'. If an item was judged as 'old' participants were then asked to judge whether this was a seen or heard item.

Arslan and Bastiaanse's (2014) findings showed that the PWA performed less accurately (64\%) in making old/new judgements than the healthy individuals who scored over 74\% accuracy rate. For a subgroup of non-fluent PWA, identifying new items were more difficult than recognizing old items, while the healthy participants and fluent PWA did not show such a pattern. Interesting patterns emerged in the PWA's source memory performances which indicated that the PWA were less successful in making seen/heard judgements as compared to healthy individuals (NBDs). This is illustrated in Figure 1.

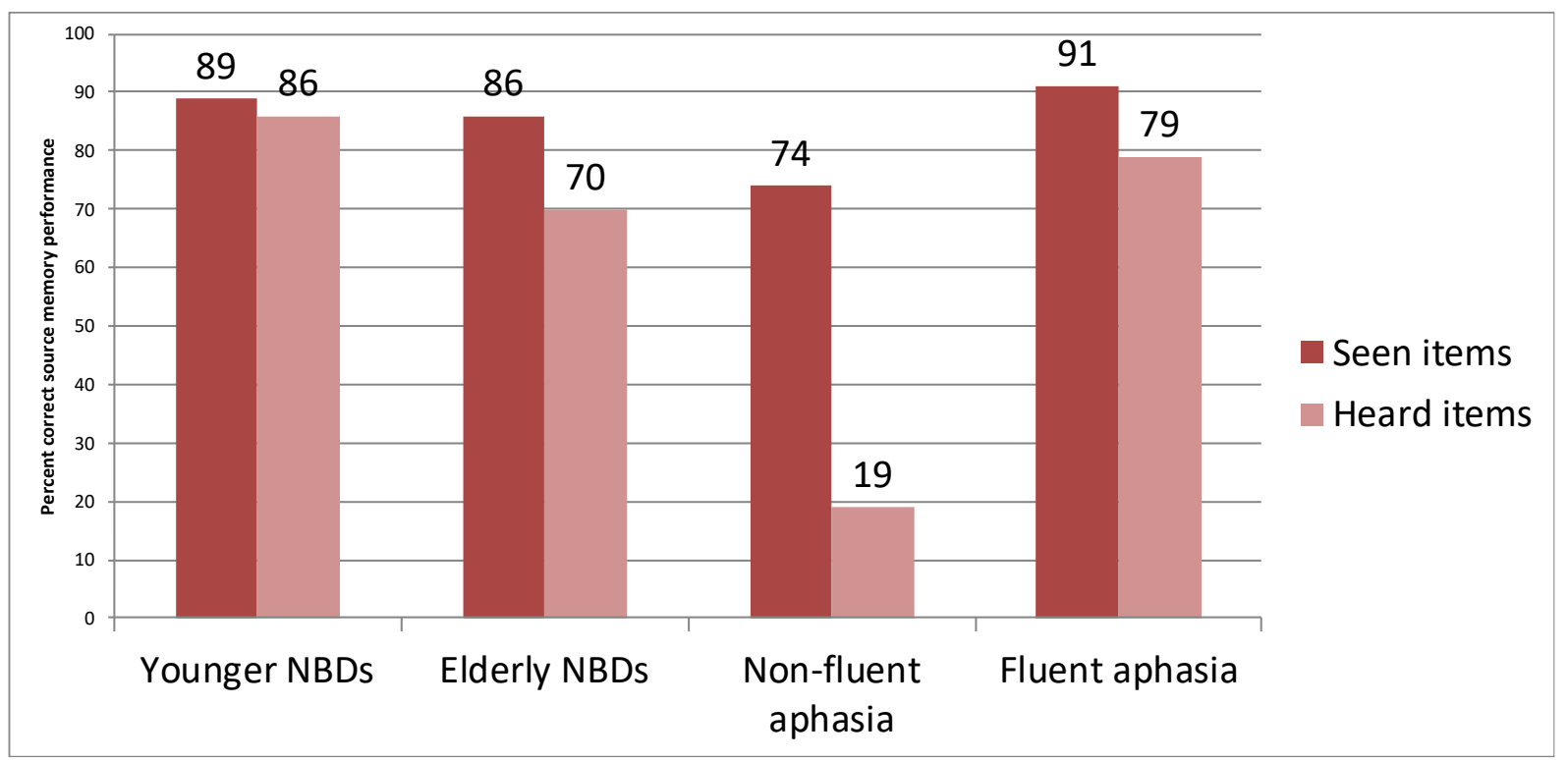

Figure 1. Percent source recall accuracy for items that are correctly judged as 'old' in the source memory task.

It was shown that the non-fluent PWA largely failed in recognizing 'heard' items with around $19 \%$ accuracy while they performed considerably better in recognizing 'seen' items (74\%). The fluent PWA and healthy aging individuals also showed a heard-seen asymmetry in their source memory performances yet to a much smaller extent than the non-fluent PWA. 
These data point to a similar pattern of source identification impairments reported in Arslan et al. (2014), suggesting that Turkish non-fluent PWA's difficulty in associating different kinds of information sources to evidential forms is partly caused by underlying source memory impairments.

\section{Conclusion}

In this overview of recent experimental studies on evidentiality in Turkish, an aim was to recapitulate emerging findings from less commonly studied populations, including persons with aphasia, and bilingual individuals living under heritage language conditions. I have presented major findings from a number of experimental studies that used offline and online measures to investigate per-millisecond time course of evidentiality processing. On this basis, I provide discussions addressing certain controversies in Turkish linguistics regarding the nature of evidentiality marking.

One of these controversies concerned whether or not the suffix -DI, which is referred to as the direct evidential here, encodes direct witnessing or firsthand information sources of the speaker. Recall that Johanson (2003) proposed that this form is an evidentiality-neutral past tense, but not a proper evidential. The experimental data reported in Arslan et al. (2015) however are at odds with this claim. This study provided clear evidence from a visual world eye-movement monitoring experiment that Turkish monolingual speakers consider the suffix DI as the direct evidentiality marker. A group of Turkish monolingual speakers participated in Arslan et al. (2015) study, showed a bewildering pattern of eye-movements, they fixated significantly long on the picture depicting in progress version of the action in question before they turned to the target picture, confirming that they require to witness the action upon hearing a sentence marked with the direct evidential -DI.

Furthermore, another set of experimental data reported in Arslan et al. (2017) showed that Turkish native speakers largely rate unacceptable the sentence stimuli that contain a direct 
evidential -DI used in a non-firsthand information context. Following Johanson (2003), who suggests that $-\mathrm{DI}$ is evidentially neutral, one would expect Turkish native speakers to judge mismatches by direct evidentials as acceptable. However, this was not what the data indicate: Turkish native speakers judge evidentiality - information source mismatches unacceptable to a great extent. Thus, the data recapitulated in this chapter largely confirm the earlier theoretical work on the direct evidential, analysing this marker as an encoder of the speaker's direct experience (e.g. Underhill 1976, Aksu-Koç and Slobin 1986, Slobin and Aksu 1982).

A second controversy concerns temporal characteristics of evidentiality in Turkish, as some scholars analyse both the evidentials as tenses whereas some others treat evidentiality as a modal distinction (i.e. non-temporal). Turkish inflectional morphemes are extremely multifunctional to mark tense-aspect-mood (the so-called TAM system), and evidentiality marking is one of the functions of this highly complex system. I have underlined in this chapter, for evidentiality marking, the actual event time is not always relevant. This is very obvious for the indirect evidential in Turkish, a relevant temporal point is the moment when the speaker receives information, which can be non-past, although the actual event perhaps happened an hour before or in the previous century.

In conclusion, on the basis of recent experimental data on evidentiality processing in both bilingualism and aphasia, it can be expressed with certainty that evidentiality in Turkish is a vulnerable domain in aphasia, and in bilingual individuals acquiring Turkish as a heritage language. First, in Turkish heritage speakers living in European countries, where evidentiality is not grammatically obligatory in language, the notion of evidentiality seems to erode due to lack of input. Second, individuals suffering from non-fluent aphasia often perform poorly in tasks that require comprehension and production of language structures referring to the past (see e.g. Bastiaanse et al. 2011). Turkish individuals with aphasia are more impaired in processing the direct evidential as compared to the indirect evidential, although their source memory for witnessed events are rather preserved (Arslan et al. 2014, Arslan and Bastiaanse 
2014). This seems to be an interesting asymmetrical impairment which warrants wider future research.

\section{References}

Aarssen, Jeroen. 2001. "Development of temporal relations in narratives by Turkish-Dutch bilingual children." In Narrative development in a multilingual context., edited by Ludo T. Verhoeven and Sven Stromqvist, 209-231. Amsterdam: Benjamins.

Aikhenvald, Alexandra Y. 2003. "Evidentiality in typological perspective." In Studies in evidentiality, edited by Alexandra Y. Aikhenvald and Robert M. W. Dixon, 1-32. Amsterdam: John Benjamins.

Aikhenvald, Alexandra Y. 2004. Evidentiality. Oxford: Oxford University Press.

Aksu-Koç, Ayhan. 1988. The acquisition of aspect and modality: The case of past reference in Turkish. Cambridge: Cambridge University Press.

Aksu-Koç, Ayhan. 2000. "Some aspects of the acquisition of evidential in Turkish." In Evidentials: Turkic, Iranian and neighbouring languages., edited by Lars Johanson and Bo Utas, 15-28. Berlin: Walter de Gruyter.

Aksu-Koç, Ayhan, and Dan I. Slobin. 1986. "A psychological account of the development and use of evidentials in Turkish." In Evidentiality. The linguistic coding of epistemiology., edited by Chafe Wallace and Johanna Nichols, 159-167. New Jersey: Ablex Publishing Corporation.

Aksu-Koç, Ayhan, Hale Ögel-Balaban, and İ Ercan Alp. 2009. "Evidentials and source knowledge in Turkish." In Evidentiality: A window into language and cognitive development, New directions for child and adolescent development, edited by Stanka A. Fitneva and Tomoko Matsui, 13-28. San Francisco: Jossey-Bass. 
Arslan, Seckin. 2015. "Neurolinguistic and Psycholinguistic Investigations on Evidentiality in Turkish." PhD Thesis, University of Groningen.

Arslan, Seckin, Ayhan Aksu-Koç, İlknur Maviş, and Roelien Bastiaanse. 2014. "Finite verb inflections for evidential categories and source identification in Turkish agrammatic Broca's aphasia." Journal of Pragmatics 70:165-181.

Arslan, Seckin, Elif Bamyac1, and Roelien Bastiaanse. 2016. "A characterization of verb use in Turkish agrammatic narrative speech." Clinical Linguistics \& Phonetics 30 (6):449-469.

Arslan, Seckin, and Roelien Bastiaanse. 2014. "Source memory impairments in aphasic and healthy aging Turkish speakers." 15th Science of Aphasia Conference, Ospedale San Camillo, Venice, Italy.

Arslan, Seckin, and Roelien Bastiaanse. Submitted. "First language exposure predicts attrition patterns in Turkish heritage speakers' use of grammatical evidentiality."

Arslan, Seckin, Roelien Bastiaanse, and Claudia Felser. 2015. "Looking at the evidence in visual world: eye-movements reveal how bilingual and monolingual Turkish speakers process grammatical evidentiality." Frontiers in Psychology 6. doi: 10.3389/fpsyg.2015.01387.

Arslan, Seckin, Dörte de Kok, and Roelien Bastiaanse. 2017. "Processing grammatical evidentiality and time reference in Turkish heritage and monolingual speakers." Bilingualism: Language and Cognition 20 (3):457-472.

Bastiaanse, Roelien, Elif Bamyaci, Chien-Ju Hsu, Jiyeon Lee, Tuba Yarbay-Duman, and Cynthia K. Thompson. 2011. "Time reference in agrammatic aphasia: A crosslinguistic study." Journal of Neurolinguistics 24 (6):652-673.

Chafe, Wallace, and Johanna Nichols. 1986. Evidentiality: The linguistic coding of epistemology. New Jersey: Ablex Publishing. 
Cinque, Guglielmo. 2001. "A note on mood, modality, tense and aspect affixes in Turkish." In The Verb in Turkish, edited by Eser Erguvanl1-Taylan, 47-59. Amsterdam: John Benjamins.

Csató, Eva A. 2000. "Turkish mis-and imis-items. Dimensions of a functional analysis." In Evidentials: Turkic, Iranian and neighbouring languages, edited by Lars Johanson and Bo Utas, 29-46. Berlin: Mouton de Gruyter.

Enç, Mürvet. 2004. "Rethinking past tense." In The syntax of time, edited by Jacqueline Guéron and Alexander Lecarme, 203-215. Cambridge, MA: MIT Press. Erguvanl1-Taylan, Eser. 1997. "The Relationship between Aspect, Tense and Modality in Turkish : the Morpheme -DI." In XI. Dilbilim Kurultayı Bildirileri, edited by D. Zeyrek and Ş Ruhi, 1-13. Ankara: Middle East Technical University Press. Johanson, Lars. 1971. Aspekt im Türkischen. Uppsala: Almqvist \& Wiksell. Johanson, Lars. 2003. "Evidentiality in Turkic." In Studies in Evidentiality, edited by Alexandra Y.; Aikhenvald and R.M.W.; Dixon, 273-290. Amsterdam: John Benjamins.

Johanson, Lars, and Bo Utas (eds.). 2000. Evidentials: Turkic, Iranian and neighbouring languages. Berlin: Walter de Gruyter.

Karakoç, Birsel. 2007. "Connectivity by means of finite elements in monolingual and bilingual Turkish discourse." In Connectivity in Grammar and Discourse, edited by Jochen Rehbein, Christiane Hohenstein and Lukas Pietsch, 199-227. Amsterdam: John Benjamins.

Kornfilt, Jaklin. 1997. Turkish. London: Routledge.

Ozturk, Ozge, and Anna Papafragou. 2016. "The acquisition of evidentiality and source monitoring." Language Learning and Development 12 (2):199-230.

Papafragou, Anna, Peggy Li, Youngon Choi, and Chung-hye Han. 2007. "Evidentiality in language and cognition." Cognition 103 (2):253-299. 
Pfaff, Carol W. 1991. "Turkish in contact with German: Language maintenance and loss among immigrant children in Berlin (West)." International Journal of the Sociology of Language 90 (1):97-130.

Pfaff, Carol W. 1993. "Turkish language development in Germany." In Immigrant languages in Europe, edited by Guus Extra and Ludo Verhoeven, 119-146. Avon: Multilingual Matters.

Plungian, Vladimir A. 2010. "Types of verbal evidentiality marking: an overview." In Linguistic realization of evidentiality in European languages, , edited by Elena Smirnova and Gabriele Diewald, 15-58. Berlin: Walter de Gruyter.

Slobin, Dan I., and Ayhan A. Aksu. 1982. "Tense, aspect and modality in the use of the Turkish evidential." In Tense-aspect: Between semantics and pragmatics, edited by Paul J. Hopper, 185-200. Amsterdam: John Benjamins.

Underhill, Robert. 1976. Turkish grammar. Cambridge, MA: MIT Press. 